\title{
Piperine inhibits cytokine production by human peripheral blood mononuclear cells
}

\author{
S. Chuchawankul ${ }^{1}$, N. Khorana ${ }^{2}$ and Y. Poovorawan ${ }^{3}$ \\ ${ }^{1}$ Innovation Center for Research and \\ Development of Medical Diagnostic Technology Project, \\ Department of Transfusion Medicine and Clinical Microbiology, \\ Faculty of Allied Health Sciences, Chulalongkorn University, Bangkok, Thailand \\ ${ }^{2}$ Department of Pharmaceutical Chemistry and Pharmacognosy, \\ Faculty of Pharmaceutical Sciences, Naresuan University, \\ Phitsanulok, Thailand \\ ${ }^{3}$ Department of Pediatrics, Faculty of Medicine, Chulalongkorn University, \\ Bangkok, Thailand \\ Corresponding author: S. Chuchawankul \\ E-mail: siriporn.ch@chula.ac.th
}

Genet. Mol. Res. 11 (1): 617-627 (2012)

Received August 16, 2011

Accepted January 27, 2012

Published March 14, 2012

DOI http://dx.doi.org/10.4238/2012.March.14.5

\begin{abstract}
Piperine, an amide isolated from Piper species (Piperaceae), has been reported to exhibit central nervous system depression, anti-pyretic and anti-inflammatory activity. Immunomodulatory and anti-tumor activity of piperine has been demonstrated in mouse carcinomas. However, there is little information available concerning the effect of piperine on humans. We evaluated the immunopharmacological activity of this compound in human immune cells. Human peripheral blood mononuclear cells (PBMCs) were exposed to piperine, and cell proliferation was determined by the MTS assay. Piperine significantly inhibited phytohemagglutinin-stimulated human PBMC proliferation after exposure for $72 \mathrm{~h}$. This compound
\end{abstract}


inhibited PBMC activity, with an $\mathrm{IC}_{50}$ of $100.73 \pm 11.16 \mu \mathrm{g} / \mathrm{mL}$. Production of interleukin-2 (IL-2) and interferon- $\gamma$ (IFN- $\gamma$ ) was measured using an ELISA assay and RT-PCR. Piperine inhibited IL-2 and IFN- $\gamma$ production in the PBMCs. RT-PCR data indicated that IL-2 and IFN- $\gamma$ mRNA expression in PBMCs is suppressed by piperine. This compound significantly inhibited the production of these two cytokines by activated PBMCs in a dose-dependent manner. In conclusion, piperine appears to have potential as an immunomodulatory agent for immune system suppression.

Key words: Piperine; Immunopharmacological activity; IL-2; IFN- $\gamma$; RT-PCR; ELISA

\section{INTRODUCTION}

Black pepper (Piper nigrum) is one of the most common spices highly consumed worldwide. Peppers have been used traditionally due to their various biological activities. A major alkaloid and active component of most Piper spp is piperine. Black pepper and piperine have been reported to exhibit central nervous system depression (Virinder et al., 1997), anti-pyretic (Virinder et al., 1997), anti-microbial (Kumar et al., 2007), and anti-inflammatory activities (Virinder et al., 1997; Pradeep and Kuttan, 2004; Kumar et al., 2007). Sunila and Kuttan (2004) showed that piperine could inhibit solid tumor development in mice induced with Dalton's lymphoma ascites cells and increase the life span of mice bearing Ehrlich ascites carcinoma tumor. In addition, piperine could inhibit the metastasis induced by B16F10 melanoma cells (Pradeep and Kuttan, 2002, 2004). Our preliminary data showed that piperine could also exhibit anti-tumor activity against human T cell lymphoma (H9), with an $\mathrm{IC}_{50}$ of $14.7 \pm 2.1 \mu \mathrm{g} / \mathrm{mL}$ (Chuchawankul et al., 2006). Moreover, treatment of Jurkat, human leukemic T cells, with piperine at concentrations of 40,80 , and $100 \mu \mathrm{g} / \mathrm{mL}$ resulted in viabilities of $44.7 \pm 4.50,40.3 \pm 1.08$, and $43.1 \pm 2.85 \%$, respectively (Ajsonjorn, 2007). However, there is relatively scarce evidence on the effect of piperine on humans, even in an in vitro model. Furthermore, the immunopharmacological activity of piperine on human peripheral blood mononuclear cells (PBMCs) has not yet been reported.

The activation and clonal expansion of T lymphocytes in human PBMCs play critical roles in the generation of immune responses. Antigens or phytohemagglutinin (PHA) can stimulate resting T cells to proliferate and differentiate (Ferreia et al., 1999). In the present investigation, we used PBMCs isolated from human peripheral blood as target cells to evaluate the immunopharmacological action of piperine. The lymphoproliferative effect of piperine on human PBMCs was determined using the 3-(4,5-dimethylthiazol-2-yl)-5-(3carboxymethoxyphenyl)-2-(4-sulfophenyl)-2H-tetrazolium (MTS) assay. The cytotoxicity of piperine on PHA-stimulated PBMCs was studied using microscopic examination to ensure that the inhibitory action of piperine was due to direct cytotoxicity. In addition, it has been previously verified by many researchers that a series of cytokines such as interleukin-2 (IL-2) and interferon- $\gamma($ IFN- $\gamma$ ) are important for the growth of PBMCs induced by antigens or PHA (Robb, 1984; Young, 1996; Chen et al., 2007). Therefore, the production and gene expression of both cytokines were examined in this study. 


\section{MATERIAL AND METHODS}

\section{Chemicals}

Commercial piperine was obtained from Fluka (Gillingham, UK). Dimethyl sulfoxide (DMSO), phosphate-buffered saline (PBS), ethidium bromide (EtBr), camptothecin, PHA, and actinocymin D were purchased from Sigma Chemicals Co. (St. Louis, MO, USA). Agarose gel was obtained from Biomidi Co. (Toulouse, France). $\mathrm{Ca}^{2+} \mathrm{Mg}^{2+}$-free Dulbecco's PBS was obtained from Promega (Madison, WI, USA) and 0.4\% Trypan blue dye from GIBCOInvitrogen (Carlsbad, CA, USA).

\section{Human subjects}

Healthy subjects were randomly recruited from blood donors of the National Blood Center, Thai Red Cross Society. Written informed consent was obtained from each participant before the start of the study. The experimental protocol was reviewed and approved by the Ethics Review Committee for Research Involving Human Research Subjects, Health Science Group, Chulalongkorn University, Bangkok, Thailand.

\section{Preparation of human PBMCs}

PBMCs were isolated from erythrocytes and granulocytes by density gradient centrifugation, as described elsewhere (Yang et al., 1999). Diluted blood samples were carefully layered on lymphoprep (Axis-Shield, Oslo, Norway). The mixture was centrifuged at $800 \mathrm{~g}$ for $20 \mathrm{~min}$ at room temperature. The PBMC layers were collected and resuspended to a concentration required for each experiment. Before the test, cells were maintained in RPMI-1640 (GIBCO-Invitrogen) containing 2 $\mathrm{mM}$ glutamine, $10 \%$ heat-inactivated fetal bovine serum (HyClone Laboratories, Inc., Logan, UT, USA), $50 \mathrm{U} / \mathrm{mL}$ penicillin, $50 \mu \mathrm{g} / \mathrm{mL}$ streptomycin, and anti-mycotic agents (GIBCO-Invitrogen) in a humidified atmosphere at $37^{\circ} \mathrm{C}$ and $5 \% \mathrm{CO}_{2}$. Cell numbers and viability were determined using a hemocytometer, and viability was assessed using Trypan blue dye exclusion method (Talwar, 1974). PBMCs were stimulated with or without $5 \mu \mathrm{g} / \mathrm{mL}$ PHA for all experiments.

\section{Lymphoproliferation test}

The in vitro immunopharmacological effect of piperine was evaluated by measuring its impact on the PBMC proliferation activity by using the MTS colorimetric technique (Goodwin et al., 1995). The MTS assay was performed according to the method described in CellTiter $96^{\circledR}$ Non-Radioactive Cell Proliferation Assay Technical Bulletin \#TB112 (Promega) with only minor modifications. PBMCs were seeded onto 96-well plates (Corning Costar; Corning, NY, USA) and exposed to DMSO (0.2-0.5\%, as control solvent) or different concentrations of piperine for 24-72 h. Actinomycin D $(1 \mu \mathrm{g} / \mathrm{mL})$ was used as a control. After treatment, $20 \mu \mathrm{L}$ MTS tetrazolium compound (Owen's reagent) was directly added to $100 \mu \mathrm{L}$ of the culture in the wells and incubated for $4 \mathrm{~h}$ in a $5 \% \mathrm{CO}_{2}$ humidified incubator at $37^{\circ} \mathrm{C}$. The MTS tetrazolium compound was bioreduced by metabolically active cells to a colored formazan product that was soluble in the tissue culture medium. In this assay, the quantity of formazan product formed is directly proportional to the number of 
viable cells in the cultures. The colored formazan is indicative of the cell metabolic state and viability. Absorbance was recorded at $492 \mathrm{~nm}$ by using a microplate reader (Anthos, model zenyth 340).

\section{Determination of the in vitro cytotoxic activity of piperine}

Total and viable cell numbers of PBMCs were counted under a microscope after Trypan blue staining. The percentage of viable cells was calculated as follows:

$$
\text { Viability }(\%)=\frac{\text { Viable cell number }}{\text { Total cell number }} \times 100
$$

\section{Determination of cytokine production in PBMCs}

PBMCs $\left(2 \times 10^{5}\right.$ cells/well $)$ were cultured with PHA alone or in combination with various concentrations of piperine $(3.125-100 \mu \mathrm{g} / \mathrm{mL})$ for $72 \mathrm{~h}$. The supernatant samples were collected and stored at $-20^{\circ} \mathrm{C}$ until use. Production of IL-2 and IFN- $\gamma$ in PBMC supernatant samples was measured using a sandwich enzyme-linked immunosorbent assay (ELISA) method (Endogen, Boston, MA, USA), according to manufacturer instructions.

\section{Extraction of total cellular RNA}

Total cellular RNA was extracted from PBMCs by using a previously described method (Kuo et al., 2002). PBMCs $\left(5 \times 10^{6}\right.$ cells) were activated with or without PHA and co-cultured with various concentrations of piperine for $18 \mathrm{~h}$. After incubation, the collected cells were lysed in Tri Reagent (Molecular Research Center, Cincinnati, OH, USA) as described in the manufacturer protocol. After centrifugation, the extracted RNA was precipitated with isopropanol. The mixture was centrifuged, and the total cellular RNA pellet was washed with $75 \%$ ethanol. Diethyl pyrocarbonate (DEPC)-treated water was added to re-dissolve the RNA pellet before further processing. The concentration of the extracted RNA was measured at an optical density of $260 \mathrm{~nm}$.

\section{Determination of mRNA expression by reverse transcription-polymerase chain reaction (RT-PCR)}

Before the RT-PCR, about $1 \mu \mathrm{g}$ total RNA was treated with RNase-free deoxyribonuclease I (DNase I) (Fermentas, Burlington, ON, Canada), according to manufacturer instructions. First-strand cDNA was synthesized from about 800 ng DNase I-treated RNA by using the ImProm-II ${ }^{\mathrm{TM}}$ Reverse Transcription System (Promega) and oligo(dT $)_{17}$ primers, as per the manufacturer protocol. RT was carried out at $50^{\circ} \mathrm{C}$ for $65 \mathrm{~min}$. After cDNA synthesis, the desired DNA fragments were amplified for 30-35 cycles by using DNA polymerase and specific primers for IL-2, IFN- $\gamma$, and $\beta$-actin transcripts as listed in Table 1. The final PCR products were subjected to electrophoresis and stained with EtBr. The DNA bands corresponding to IL-2, IFN- $\gamma$, and $\beta$-actin transcripts were 229,435 , and $656 \mathrm{bp}$, respectively.

\section{Statistical analysis}

Results are reported as means \pm standard deviation of at least three bioassay experi- 
ments and compared using analysis of variance (ANOVA). Differences were considered to be statistically significant when $\mathrm{P}<0.05$. All band densities in the RT-PCR method were analyzed by the 1-D MultiLane Densitometry program by using an AlphaImager 2000 (Alpha Innotech Corp., San Leandro, CA, USA).

Table 1. Nucleotide sequences of the primers used for amplification of cytokines in PBMCs.

\begin{tabular}{llccc}
\hline Target gene & Primer sequence & Ta $\left({ }^{\circ} \mathrm{C}\right)$ & Length $(\mathrm{bp})$ & Reference \\
\hline IL-2 sense & 5'-GAATGGAATTAATAATTACAAGAATCCC-3' & 53 & 229 & Breen et al. (2000) \\
IL-2 anti-sense & 5'-TGTTCAGATCCCTTTAGTTCCAG-3' & & & \\
IFN- $\gamma$ sense & 5'-CTGCATCGTTTTGGGTTCTCT-3' & 58 & 435 & This study* \\
$\begin{array}{l}\text { IFN- } \gamma \text { anti-sense } \\
\beta \text {-actin sense }\end{array}$ & 5'-ATCTGACTCCTTTTTCGCTTCC-3' & & & \\
$\beta$-actin anti-sense & 5'-ACGGGTCACCCACACTGTGC-3' & 53 & 656 & Fisker et al. (2004) \\
\hline
\end{tabular}

$\mathrm{Ta}=$ optimal annealing temperature. ${ }^{*}$ Primers of the human IFN- $\gamma$ gene were designed based on the GenBank accession No. NM-000619.

\section{RESULTS}

\section{Piperine inhibits human PBMC proliferation induced by PHA}

Piperine's effect on human PBMC proliferation was studied by treating resting cells or PHA-activated cells with $0.1-100 \mu \mathrm{g} / \mathrm{mL}$ piperine for 24,48 , and $72 \mathrm{~h}$. Cell proliferation was determined using non-radioactive cell proliferation assay or MTS assay. Significant effects on PHA-stimulated PBMC proliferation were noted after 24-72 $\mathrm{h}$ treatment with 10-100 $\mu \mathrm{g} / \mathrm{mL}$ piperine. Moreover, after $72 \mathrm{~h}$ treatment, $100 \mu \mathrm{g} / \mathrm{mL}$ piperine reduced the viability of PHA-stimulated PBMCs to $48.2 \pm 14.2 \%$ (Figure 1). Piperine induced its inhibitory effect on PHA-activated PBMC proliferation in both time-dependent and concentration-dependent fashion. In addition, piperine had no significant effect on the proliferation of non-stimulated PBMCs (data not shown).

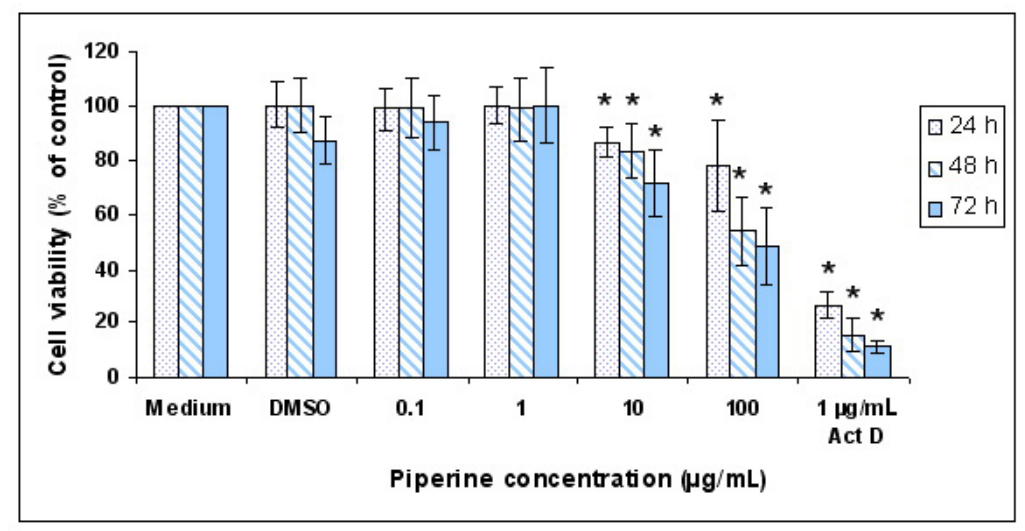

Figure 1. PHA-stimulated PBMCs were treated with $1-100 \mu \mathrm{g} / \mathrm{mL}$ piperine for $72 \mathrm{~h}$, after which cell proliferation was determined using MTS assay, a non-radioactive cell proliferation assay. The percentage of cell viability was calculated. Actinomycin D (Act D), a known anti-cancer drug, at $1 \mu \mathrm{g} / \mathrm{mL}$, was used as a positive control. The results are reported as means $\pm \mathrm{SD}$. Asterisks indicate significant difference from control $(\mathrm{P}<0.05)$. 
As shown in Figure 1, after $72 \mathrm{~h}$ treatment, piperine inhibited the proliferation of PHA-activated PBMCs at an $\mathrm{IC}_{50}$ of $100.73 \pm 11.16 \mu \mathrm{g} / \mathrm{mL}$. PBMC proliferation was not affected by $0.2 \%$ DMSO. Importantly, actinomycin D, a known anti-cancer drug, also significantly inhibited the proliferation of PHA-stimulated PBMCs. Actinomycin D is primarily used to inhibit transcription. It is also widely used as a clinical anti-tumor drug. We compared piperine's effect on PBMC proliferation with that of actinomycin D. When activated PBMCs were cultured with $1 \mu \mathrm{g} / \mathrm{mL}$ piperine for 24,48 , and $72 \mathrm{~h}$, the viability of PBMCs from 5 volunteers still remained at about $100 \%$, whereas that in the case of actinomycin $\mathrm{D}(1 \mu \mathrm{g} / \mathrm{mL})$ was about $26.6,15.4$, and $11.5 \%$, respectively. Thus, actinomycin $\mathrm{D}$ was more toxic to normal PBMCs than piperine.

In our model, the maximal concentration of piperine used was limited due to its solubility. Furthermore, the percentage of DMSO used to solubilize the compound could not be increased beyond $0.2 \%$ for all concentrations tested. To overcome this limitation, we tested PBMCs with piperine dissolved in numerous types of solvent. None of them showed better solubility without causing toxicity to the cells themselves. Hence, the maximal dosages of piperine in this model were selected on the basis of its solubility. Moreover, higher concentrations of piperine $(>100 \mu \mathrm{g} / \mathrm{mL})$ might efficiently inhibit human PBMC proliferation or possibly be toxic to the cells.

\section{Piperine induced no toxicity in PBMCs}

To ensure that the inhibitory mechanisms of piperine toward PBMC proliferation were not because of direct toxicity to the cells, we studied the cytotoxicity of piperine in PBMCs. PBMCs with or without PHA were cultured with various concentrations of piperine for 18,48 , and $96 \mathrm{~h}$. Total viable cell numbers were counted under a microscope following Trypan blue staining. The percentages of viable cells were calculated. The viability of PBMCs after treatment with $100 \mu \mathrm{g} / \mathrm{mL}$ piperine for 18 and $48 \mathrm{~h}$ was 96.15 and $86.66 \%$, respectively (viability of the medium control cells, 100\%). Moreover, incubation of PBMCs for $96 \mathrm{~h}$ after treatment with $100 \mu \mathrm{g} / \mathrm{mL}$ piperine resulted in viability of about $71.43 \%$. In these experiments, the compound showed less toxicity to human PBMCs as evaluated by the Trypan blue exclusion method.

\section{Effects of piperine on IL-2 and IFN- $\gamma$ levels measured using ELISA}

Immunopharmacological activity of a compound can be measured by detecting the changes in the production of immune molecules such as cytokines. To elucidate the molecular mechanisms underlying piperine's biological effect on human PBMCs, we measured the levels of IL-2 and IFN- $\gamma$ by using ELISA and RT-PCR. ELISA results showed that IL-2 production was increased in the cells treated with $1-25 \mu \mathrm{g} / \mathrm{mL}$ piperine (Figure $2 \mathrm{~A}$ ). As expected, 50$100 \mu \mathrm{g} / \mathrm{mL}$ piperine suppressed IL-2 production as compared to the control solvent. Piperine induced a biphasic effect on IL-2 production. The compound stimulated and suppressed IL-2 production at low and high concentrations, respectively.

IFN- $\gamma$ production was significantly inhibited by 25,50 , and $100 \mu \mathrm{g} / \mathrm{mL}$ piperine in a dose-dependent manner (Figure 2B). Interestingly, the anti-leukemic drug camptothecin also significantly inhibited the production of both IL-2 and IFN- $\gamma$. 

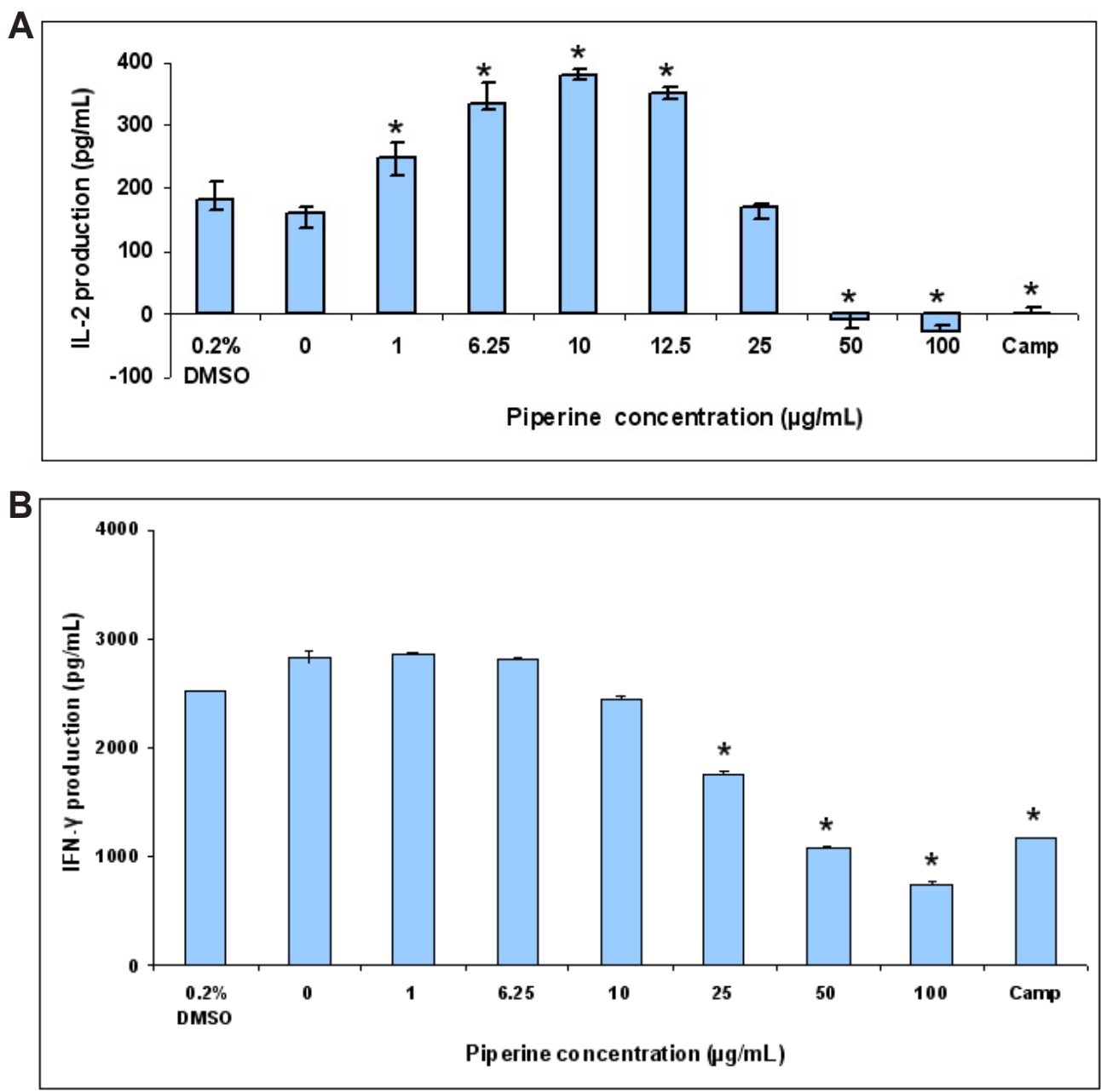

Figure 2. PBMCs $\left(2 \times 10^{5}\right.$ cells/well) were cultured with PHA alone or in combination with various concentrations of piperine $(1-100 \mu \mathrm{g} / \mathrm{mL})$ for $72 \mathrm{~h}$. Camptothecin (Camp) at $143 \mathrm{nM}$, was used as a control. The supernatants were then collected and stored at $-20^{\circ} \mathrm{C}$ until use. Productions of IL-2 (A) and IFN- $\gamma$ (B) in PBMC supernatants were measured by a sandwich enzyme-linked immunosorbent assay (ELISA) method (Endogen, Boston, MA, USA). The results are reported as mean optical density with SD in triplicate cultures. Asterisks indicate significant difference from control $(\mathrm{P}<0.05)$. Piperine showed no effect on PHA-unstimulated PBMCs as shown in the adjacent bars coupled with each result.

\section{Effects of piperine on IL-2 and IFN- $\gamma$ mRNA levels measured using RT-PCR}

To determine whether the inhibition of cytokine production in activated PBMCs treated with piperine was due to a transcriptional impact, we extracted total RNA from treated cells and determined the levels of IL-2 and IFN- $\gamma$ mRNA by using semi-quantitative RT-PCR. Piperine had no remarkable impact on the mRNA levels of the cytokines (Figure 3). The normalized mRNA levels of IFN- $\gamma$ and IL-2 were consistent with the protein levels of IFN- $\gamma$ and IL-2. 


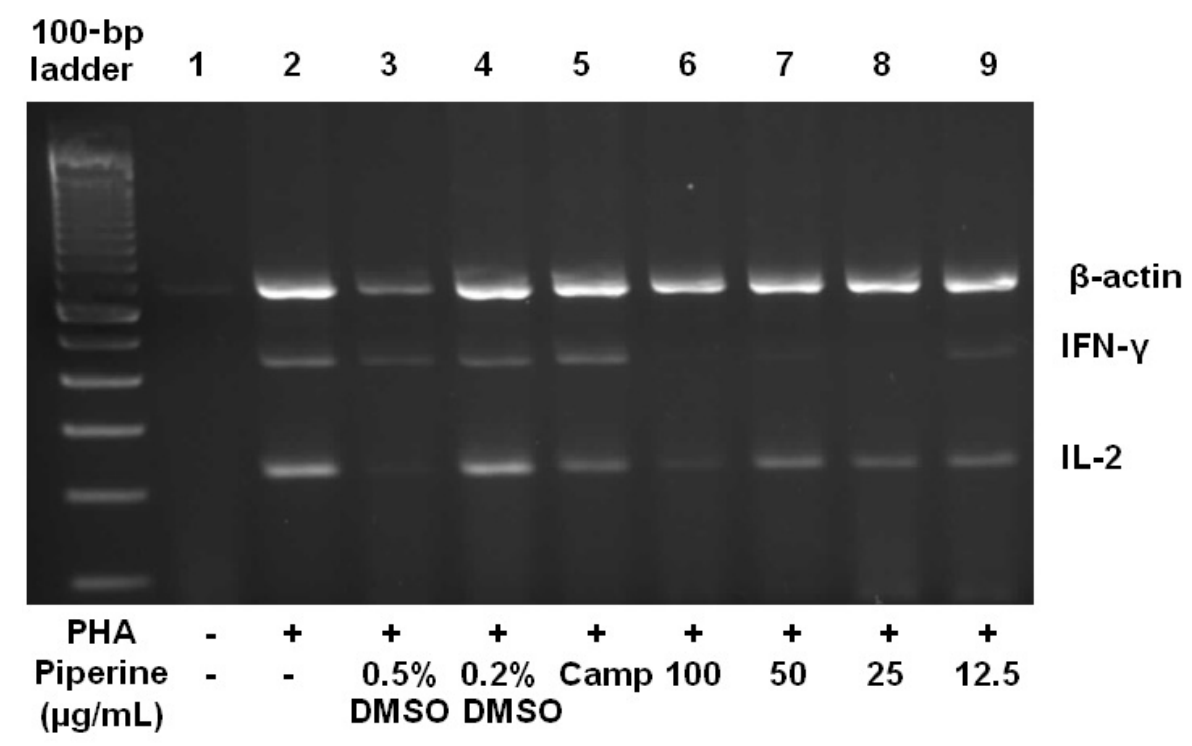

Figure 3. RT-PCR analysis of IL-12 and IFN- $\gamma$ expression in phytohemagglutinin (PHA)-stimulated human PBMCs treated with decreasing piperine concentrations $(100,50,25,12.5$, and $0 \mu \mathrm{g} / \mathrm{mL})$ for $18 \mathrm{~h}$. Representative result is shown on $2 \%$ agarose gel electrophoresis displaying mRNA transcripts of IL-12, IFN- $\gamma$ and $\beta$-actin. A 100bp DNA ladder was shown. Lane $1=$ negative control; lane $2=$ PHA-stimulated PBMCs; lanes 3 and $4=0.5$ and $0.2 \%$ DMSO, respectively; lane $5=$ camptothecin (Camp); lanes 6 to $9=$ decreasing piperine concentrations used for treating PHA-stimulated PBMCs.

\section{DISCUSSION}

Immunomodulating and anti-tumor properties of several medicinal plants, including those producing piperine, have long been studied worldwide. Piperine at a concentration of 50 $\mu \mathrm{g} / \mathrm{mL}$ was found to produce cytotoxicity in cultured L929 mouse fibroblast cells. In addition, piperine ( $1.14 \mathrm{mg} \cdot$ animal $^{-1} \cdot \mathrm{day}^{-1}$, for 5 consecutive days) could inhibit the development of solid tumors in mice induced with Dalton's lymphoma ascites cells. Interestingly, ascites tumorbearing animals survived only $15 \pm 0.8$ days after the tumor induction while the piperine-treated animals survived $23.8 \pm 2.4$ days with an increase in life span of $58.8 \%$ (Sunila and Kuttan, 2004). Certain studies have shown that piperine could also inhibit the metastasis induced by B16F10 melanoma cells (Pradeep and Kuttan, 2002, 2004). We found in this study that piperine inhibits PBMC proliferation at an $\mathrm{IC}_{50}$ of $100.73 \pm 11.16 \mu \mathrm{g} / \mathrm{mL}$, compared to its activity in various human leukemic cell lines ( $\mathrm{IC}_{50}$ ranging from 17 to $57 \mu \mathrm{g} / \mathrm{mL}$; data not shown).

We found that $10-100 \mu \mathrm{g} / \mathrm{mL}$ piperine significantly inhibited PHA-activated PBMC proliferation in a dose- and time-dependent manner (Figure 1). In fact, the compound exhibited minor cytotoxicity even after $96 \mathrm{~h}$ treatment.

Piperine has been shown to inhibit eosinophil infiltration and airway hyperresponsiveness by suppressing T cell activity and Th2 cytokine production in an ovalbumin-induced asthma model (Kim and Lee, 2009). However, it also caused an increase in the circulating antibody titer and antibody-forming cells, as well as enhanced bone marrow cellularity and $\alpha$-esterase 
positive cells (Sunila and Kuttan, 2004). Other researchers have reported the in vitro cytoprotective and immunomodulating properties of piperine in murine splenocytes (Pathak and Khandelwal, 2007). Piperine has been shown to mitigate the adverse effects of cadmium on cytokines (IL-2 and IFN- $\gamma$ ) and cell proliferative mitogenic response (Pathak and Khandelwal, 2009). These data on cadmium- and piperine-exposed splenic cells could explain the chemopreventive action of piperine since it retained the normal immune responsive behavior of viable cells.

Activation and clonal expansion of human PBMCs, which mostly contain T lymphocytes, play vital roles in the generation of immune responses (Charles Jr. et al., 1997; Kuby, 1997). Previous studies have shown that a series of cytokines such as IL- 2 and IFN- $\gamma$ are important in the growth of antigen- or PHA-induced PBMCs (Robb, 1984; Young, 1996; Chen et al., 2007). PHA, a T lymphocyte mitogen, stimulates the proliferation of $\mathrm{T}$ cells by interacting with the $\mathrm{N}$-acetylgalactosamine glycoproteins expressed on the cells (Janeway et al., 1997). In the present study, T cells were the major proliferating cells in PHA-induced activated PBMCs. Thus, the inhibitory effect of piperine on PHA-activated PBMC proliferation might have been caused by the suppression of $\mathrm{T}$ cell proliferation. Interaction of $\mathrm{T}$ cells with antigens or mitogens is known to initiate a cascade of genes such as $I L-2$ and $I F N-\gamma$ that induces resting T cells to enter the cell cycle $\left(\mathrm{G}_{0}-\mathrm{G}_{1}\right.$ transition) and results in the expression of the high affinity receptor for IL-2 and secretion of IL-2 (Janeway et al., 1997). In response to IL-2, activated T cells progress through the cell cycle, proliferate, and differentiate into memory cells or effector cells.

Many studies have indicated that the production of cytokines such as IL-2 and IFN- $\gamma$ is involved in the regulation of $\mathrm{PBMC}$ proliferation. The agents that affect $\mathrm{PBMC}$ proliferation are likely to control the expression or function of IL-2 and IFN- $\gamma$ (Ajchenbaum et al., 1993; Janeway et al., 1997). Our results showed that $50-100 \mu \mathrm{g} / \mathrm{mL}$ piperine significantly reduced IL-2 production in PHA-stimulated PBMCs. In contrast, at low concentrations (1-12.5 $\mu \mathrm{g} /$ $\mathrm{mL}$ ), piperine significantly increased IL-2 production. Proliferation of T cells is activated by IL-2 cytokines bound to their IL-2 receptors (Taniguchi, 1992). However, excess amounts of IL-2 do not induce higher T cell proliferation (Figure 1A).

In PHA-stimulated PBMCs, IFN- $\gamma$ levels increased or decreased concomitantly with IL-2 levels (Rohit et al., 1998). Higher concentrations of piperine significantly decreased IFN- $\gamma$ level as well as IL-2 level. Moreover, we also showed that $0.2 \%$ DMSO did not inhibit IL- 2 and IFN- $\gamma$ production in PBMCs, thereby suggesting that piperine-mediated suppression of cytokine production is not due to DMSO.

We speculated that the effects of piperine on PBMC proliferation may partly be due to the decrease in IL- 2 and IFN- $\gamma$ production. The impairments of IL- 2 and IFN- $\gamma$ production are in accordance with our hypothesis that piperine suppresses the respective mRNA transcripts. Since PBMC proliferation is primarily mediated by IL-2, inhibition of IL-2 production is the central mechanism of several immunosuppressants, including cyclosporin A. Cyclosporin A also suppresses the activation and proliferation of $\mathrm{T}$ cells by inhibiting IL-2 transcription (Schreiber and Crabtree, 1992). Hence, the suppression of IL-2 and IFN- $\gamma$ production is the reason that PBMCs fail to proliferate.

Another possible mechanism of piperine on PBMC proliferation could be shown by cell cycle analysis. Piperine, like the immunosuppressive agent rapamycin, may retain $\mathrm{T}$ cells predominantly in either the $\mathrm{G}_{0} / \mathrm{G}_{1}$ phase or the early S phase of the cell cycle (Schreiber and Crabtree, 1992; Hleb et al., 2004). That is, the compound could inhibit cell cycle progression and arrest the cells in the $\mathrm{G}_{1}$ phase. 
Differences in the mRNA expression levels were not as remarkable as those for protein levels. Although there were significant differences in cytokine levels, their corresponding mRNA transcript levels were not significantly different between piperine-treated and -untreated samples. It should be noted that cytokine levels were measured after $72 \mathrm{~h}$ treatment, while mRNA levels were measured after $18 \mathrm{~h}$ treatment. Another limitation of our study is that conventional RT-PCR has lower sensitivity than real-time PCR. Hence, a significant correlation between mRNA and protein levels was not observed ( $r^{2}=$ about 0.6; Hegde et al., 2003).

Our results suggest that black pepper might be an immunomodulatory source that can potentially alter cytokine secretion by human PBMCs and affect its putative pharmacological activities.

In conclusion, immunomodulation of the immune response by pharmacological agents can provide an alternative chemotherapeutic option for a variety of diseases such as autoimmune diseases, immunodeficiency diseases, hypersensitivity reactions, and transplantation. Piperine may not be very effective in acting as an anti-leukemic agent; however, it can be used as a potential immunomodulator for human immune suppression.

\section{ACKNOWLEDGMENTS}

We would like to thank the Asahi Glass Foundation, 2007 (Oversea Research Grants) for financial support. Research partially supported by the Commission on Higher Education and Thailand Research Fund (\#MRG 4880027) and the Innovation Center for Research and Development in Medical Diagnostic Technology Project under Chulalongkorn University Centenary Academic Development Project (Chula 100 years). The authors gratefully acknowledge the Department of Transfusion Medicine and Clinical Microbiology, Faculty of Allied Health Sciences, Chulalongkorn University, for allowing us to use their facilities. The authors also thank Varaporn Rakkhitawatthana (Graduate Program in Clinical Biochemistry and Molecular Medicine, Department of Clinical Chemistry, Faculty of Allied Health Sciences, Chulalongkorn University) for her excellent technical assistance in some experiments of our present study.

\section{REFERENCES}

Ajchenbaum F, Ando K, DeCaprio JA and Griffin JD (1993). Independent regulation of human D-type cyclin gene expression during G1 phase in primary human T lymphocytes. J. Biol. Chem. 268: 4113-4119.

Ajsonjorn S (2007). In Vitro Studies of Piperine's Antitumor Activity on Various Cancer Cells. Master's thesis, Chulalongkron University, Bangkok.

Breen EC, McDonald M, Fan J, Boscardin J, et al. (2000). Cytokine gene expression occurs more rapidly in stimulated peripheral blood mononuclear cells from human immunodeficiency virus-infected persons. Clin. Diagn. Lab. Immunol. 7: 769-773.

Charles AJ Jr, Paul T, Hunt S and Walport M (1997). Immunobiology. Current Biology Ltd., New York.

Chen YC, Tsai WJ, Wu MH, Lin LC, et al. (2007). Suberosin inhibits human peripheral blood mononuclear cells proliferation through the modulation of NF-AT and NF-KB transcription factors. Br. J. Pharmacol. 150: 298-312.

Chuchawankul S, Ajsonjorn S, Khorana N and Pooworawan Y (2006). Anti-proliferative effect of piperine on human tumor cells. J. Med. Tech. Assoc. Thai. 34: 1496-1505.

Ferreira V, Sidenius N, Tarantino N, Hubert P, et al. (1999). In vivo inhibition of NF-kB in T-lineage cells leads to a dramatic decrease in cell proliferation and cytokine production and to increased cell apoptosis in response to mitogenic stimuli, but not to abnormal thymopoiesis. J. Immunol. 162: 6442-6450.

Fisker S, Hansen B, Fuglsang J, Kristensen K, et al. (2004). Gene expression of the GH receptor in subcutaneous and intraabdominal fat in healthy females: relationship to GH-binding protein. Eur. J. Endocrinol. 150: 773-777.

Goodwin CJ, Holt SJ, Downes S and Marshall NJ (1995). Microculture tetrazolium assays: a comparison between two new 
tetrazolium salts, XTT and MTS. J. Immunol. Methods 179: 95-103.

Hegde PS, White IR and Debouck C (2003). Interplay of transcriptomics and proteomics. Curr. Opin. Biotechnol. 14: $647-651$.

Hleb M, Murphy S, Wagner EF, Hanna NN, et al. (2004). Evidence for cyclin D3 as a novel target of rapamycin in human T lymphocytes. J. Biol. Chem. 279: 31948-31955.

Janeway CA, Travers P, Hunt S and Walport M (1997). Immunobiology: The Immune System in Health and Disease. Garland Publishing Inc., New York.

Kim SH and Lee YC (2009). Piperine inhibits eosinophil infiltration and airway hyperresponsiveness by suppressing T cell activity and Th2 cytokine production in the ovalbumin-induced asthma model. J. Pharm. Pharmacol. 61: 353-359.

Kuby J (1997). Immunology. W.H. Freeman and Company, New York.

Kumar S, Singhal V, Roshan R, Sharma A, et al. (2007). Piperine inhibits TNF- $\alpha$ induced adhesion of neutrophils to

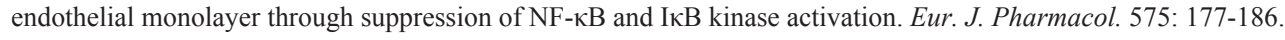

Kuo YC, Huang YL, Chen CC, Lin YS, et al. (2002). Cell cycle progression and cytokine gene expression of human peripheral blood mononuclear cells modulated by Agaricus blazei. J. Lab. Clin. Med. 140: 176-187.

Pathak N and Khandelwal S (2007). Cytoprotective and immunomodulating properties of piperine on murine splenocytes: an in vitro study. Eur. J. Pharmacol. 576: 160-170.

Pathak N and Khandelwal S (2009). Immunomodulatory role of piperine in cadmium induced thymic atrophy and splenomegaly in mice. Environ Toxicol. Pharmacol. 28: 52-60.

Pradeep CR and Kuttan G (2002). Effect of piperine on the inhibition of lung metastasis induced B16F-10 melanoma cells in mice. Clin. Exp. Metastasis 19: 703-708.

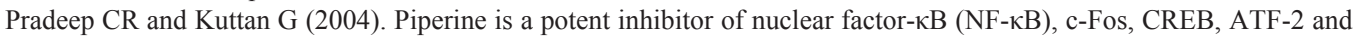
proinflammatory cytokine gene expression in B16F-10 melanoma cells. Int. Immunopharmacol. 4: 1795-1803.

Robb RJ (1984). Interleukin 2: the molecule and its function. Immunol. Today 5: 203-209.

Rohit KK, Sachanandani D, Carolyn P and Michael ML (1998). Cytokine production in cell culture by peripheral blood mononuclear cells from immunocompetent hosts. Clin. Diagn. Lab. Immunol. 5: 78-81.

Schreiber SL and Crabtree GR (1992). The mechanism of action of cyclosporin A and FK506. Immunol. Today 13: 136-142.

Sunila ES and Kuttan G (2004). Immunomodulatory and antitumor activity of Piper longum Linn. and piperine. J. Ethnopharmacol. 90: 339-346.

Talwar GP (Editor) (1974). Hand Book of Practical Immunology. National Book Trust, New Delhi.

Taniguchi T (1992). Structure and function of IL-2 and IL-2 receptors. Behring Inst. Mitt. 87-95.

Virinder SP, Subash CJ, Kirpal SB, Rajani J, et al. (1997). Phytochemistry of genus Piper. Phytochemistry 46: 597-673.

Yang NS, Chou CJ, Lin LC, Tsai WJ, et al. (1999). Evaluation of Chinese herbs that affect the cell-mediated immunity (III). J. Chin. Med. 10: 179-188.

Young HA (1996). Regulation of interferon-gamma gene expression. J. Interferon Cytokine Res. 16: 563-568. 